\title{
Research on the Measurement error of Electric Energy Metering System under Harmonics
}

\author{
J.T. Yang, J. Le, K.P. Liu \\ School of Electrical Engineering \\ Wuhan University \\ China
}

\begin{abstract}
Electric energy metering system consists of watt-hour meter, voltage transformer and current transformer. Hence, the error of electric energy metering system should be analyzed from the three parts. Aiming at the measurement accuracy of the power metering system under harmonics, the equivalent circuits of electronic watt-hour meter, capacitive voltage transformer and magnetic current transformer under harmonic conditions are built, and the harmonic measurement/metering error and the influencing factors are analyzed. The model of electric energy metering system is set up to analyze its error under harmonic conditions. This article provides a theoretical basis for the quantitative analysis of measurement error of the energy metering system under harmonics.
\end{abstract}

Keywords-watthour measurement; harmonics; watthour meter; CVT; CT

\section{INTRODUCTION}

Electric energy metering device is the basis of economic settlement between electric users, whose accuracy has direct link to the economic interests between both parts [1].Electric energy metering system is mainly composed of voltage transformer, current transformer, secondary circuit and watthour meter [2].Under harmonics, the working condition of each component will change, which leads to the increase of measurement error. The study of the measurement error under harmonics is mainly concentrated in the influence of harmonics to watt-hour meter. In most researches, the error of electric energy metering system is divided. In reference [3], the whole error of electric energy metering system is calculated by adding the error of each part together. By adding the errors together, the actual error is amplificated. The error source of electric energy metering system is comprehensively analyzed. Through theoretical analysis and simulation experiment, the error of all parts of electric energy metering system and the whole system under harmonics are analyzed.

\section{THE ERROR OF ELECTRIC METERING SYSTEM UNDER HARMONIC}

\section{A. Harmonic Measurement Error of Electronic Watt-Hour Meter}

Watt-hour meter can be divided into electromechanical and electronic watt-hour meter. Only electronic watt-hour meter is analyzed in this paper.

1) Watt-hour meter with analog multiplier:The watt-hour meter with analog multiplieris mainly consists of input part, multiplier, voltage frequency conversion part and output part.

\author{
N. Wang \\ Jiangsu Electric Power Maintenance Company Branch Huaian \\ Division \\ China
}

Firstly, the input voltage and current signal are transformed to the signal that can be accepted by multiplier and the average power over a period of time can be obtained, then the average power signal is transformed into pulse frequency signal, through counting the frequency signal, the energy can be gotten.

Assume that the two input signal of time division multiplier is $\mathrm{h}$ harmonic. The voltage signal is $u_{U h}=\sqrt{2} A_{h} \sin \omega_{h} t$ and the current signal is $u_{I h}=\sqrt{2} B_{h} \sin \left(\omega_{h} t+\psi_{h}\right)$.Assume the Modulation frequency is $\mathrm{F}$, then $n_{1}=F / f_{1}$ is the number of fundamental wave divided in one period while the $\mathrm{h}$ harmonic is divided $n_{h}$ times, where $n_{h}=n_{1} / h$.

Under $\mathrm{h}$ harmonic, $u_{U h}, u_{I h}$ are divided, the kth can be marked as $u_{h k}, u_{I h k}$ :

$$
\begin{aligned}
& u_{U h k}=\frac{n_{1} A_{h}}{\sqrt{2} \pi}\left[\cos \frac{2(k-1) h \pi}{n_{1}}-\cos \frac{2 k h \pi}{n_{1}}\right] \\
& u_{I h k}=\frac{n_{1} B_{h}}{\sqrt{2} \pi}\left[\cos \left(\frac{2(k-1) h \pi}{n_{1}}+\psi_{h}\right)-\cos \left(\frac{2 k h \pi}{n_{1}}+\psi_{h}\right)\right] \\
& P_{h}=\frac{n_{1} A_{h} B_{h} \cos \psi_{h}}{2 h^{2} \pi^{2}} \sum_{k=1}^{n_{1}}\left[\cos \frac{2(k-1) h \pi}{n_{1}}-\cos \frac{2 k h \pi}{n_{1}}\right]^{2}
\end{aligned}
$$

The harmonic power measurement value of h harmonic $P_{h}$ and the calculation value $P_{h s}$ :

$$
\begin{gathered}
P_{h}-P_{h s}=A_{h} B_{h} \cos \psi_{h} \cdot\left\{\frac{n_{1}}{2 h^{2} \pi^{2}} \sum_{k=1}^{n_{1}}\left[\cos \frac{2(k-1) h \pi}{n_{1}}-\cos \frac{2 k h \pi}{n_{1}}\right]^{2}-1\right\} \\
\text { Assume } K_{h}=\frac{n_{1}}{2 h^{2} \pi^{2}} \sum_{k=1}^{n_{1}}\left[\cos \frac{2(k-1) h \pi}{n_{1}}-\cos \frac{2 k h \pi}{n_{1}}\right]^{2}
\end{gathered}
$$

The measurement error of $\mathrm{h}$ harmonic

$$
e_{P h}=\left(K_{h}-1\right) \times 100 \% \text {. }
$$

2) Digital watt hour meter: The error of digital watt-hour meter mainly comes from the digital multiplier. Digital multiplier is mainly composed of sampling and A/D conversion.

Assume the input signals are $\mathrm{h}$ harmonic is $u_{h}\left(t_{k}\right)=\sqrt{2} A_{h} \sin \omega_{h} t_{k} \quad$ and $\quad i_{h}\left(t_{k}\right)=\sqrt{2} B_{h} \sin \left(\omega_{h} t_{k}+\psi_{h}\right) \quad$.The 
Sampling interval $t_{k}=t_{1}+(k-1) \Delta t$. The product $P_{1 k}=U_{U 1 k} U_{I 1 k}$, The measurement values within time $\mathrm{T}$ can be presented:

$$
W_{h}=2 A_{h} B_{h} \sum_{k=1}^{n} \sin \omega_{h}\left(t_{1}+(k-1) \Delta t\right) \sin \left[\omega_{h}\left(t_{1}+(k-1) \Delta t\right)+\psi_{h}\right] \Delta t
$$

According to the related literature research conclusion, for the sine signal, the relative error $\delta$ caused by the A/D conversion can be obtained as $\delta=2^{-b} \sqrt{\frac{6}{N}}$, in which, b is the $\mathrm{AD}$ converter digit, $\mathrm{N}$ is sampling number in one period.

\section{B. Analysis of CVT Harmonic Measurement Error}

Under the condition of harmonic, the stray and coupling capacitance of each part cannot be ignored .The Equivalent circuit model can be established [3]:

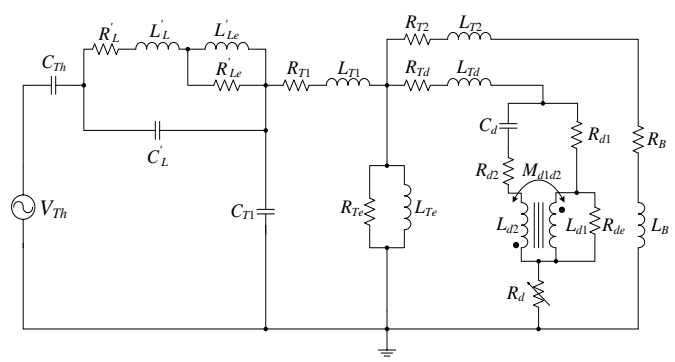

FIGURE I. THE EQUIVALENT CIRCUIT OF CVT.

In which, $V_{T h}$ is Equivalent source, The parameters of this model can consult reference [4] and [5].

The Capacitive voltage divider (in Figure 3, which is consists of $\mathrm{C} 1$ and $\mathrm{C} 2$ ). The transformation ratio is

$$
k=\frac{V_{T h}}{V_{1}}=\frac{C_{1}}{C_{1}+C_{2}}
$$

With no resonance occurs, this voltage is equal on both ends $V_{2}=V_{T h}$.

In actual, under harmonics, resonance exists between internal components. To describe the transformation degree between the two voltages, $\mathrm{k}$ is introduced: $k^{\prime}=\frac{V_{2}}{V_{T h}}$.In this model,the measurement error of CVT $e$ is:

$$
e=\frac{V_{2}-V_{T h}}{V_{T h}} \times 100 \%
$$

\section{Analysis of CT Measurement Error}

The equivalent circuit of current transformer is shown in figure 2,I1'is the primary side current Converted to the secondary side, similary, R'm and $L^{\prime} m$ is the ecitation resistance and inductance Converted to the secondary side, R2 and $\mathrm{L} 2, \mathrm{Rb}$ and $\mathrm{Lb}$ respectively are secondary side impedance and load impedance.

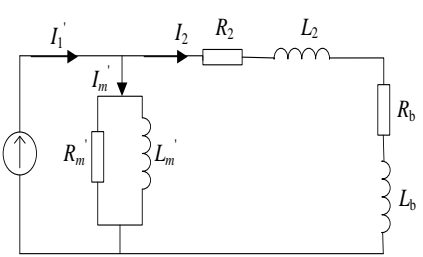

FIGURE II. THE MINIMALIST EQUIVALENT CIRCUIT OF CT.

The transformation ratio is $k=\mathrm{N}_{1} / \mathrm{N}_{2}$,

$$
\boldsymbol{I}_{1}^{\prime}=k \boldsymbol{I}_{1}, \boldsymbol{I}_{m}{ }^{\prime}=k \boldsymbol{I}_{m}, \boldsymbol{R}_{m}{ }^{\prime}=\frac{\boldsymbol{R}_{m}}{\boldsymbol{k}^{2}}, \boldsymbol{L}_{m}{ }^{\prime}=\frac{\boldsymbol{L}_{m}}{\boldsymbol{k}^{2}}
$$

At ideal condition, $I_{1}=I_{2}$. While under harmonics, the measurement has errors. The measurement error of $\mathrm{CT}$ is:

$$
e=\frac{I_{2}-I_{1}^{\prime}}{I_{1}^{\prime}} \times 100 \%
$$

\section{ANALYSIS OF THE ERROR OF ELECTRIC ENERGY METERING SYSTEM UNDER HARMONICS}

Electric energy metering system is composed of voltage transformer, current transformer, measurement of the secondary circuit and watt-hour meter.

High level voltage and current are transformed and then through transformer transformation firstly, and then give to the watt-hour meter.Power value is calculated by watt-hour meter.

The above analysis shows that each part of electric energy metering system will produce error. Figure 3 presents the compositions of errors:

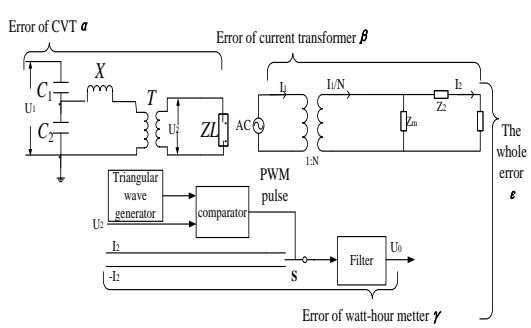

FIGURE III. MEASUREMENT ERRORS OF ELECTRIC ENERGY METERING SYSTEM.

The error referred in the Figure includes amplitude and phase error. Under the condition of single harmonic, CVT and (CT), respectively, shift the phase of voltage and current, which increases the error of watt-hour meter.

\section{The Simulation}

\section{A. The Simulation of CVT Error under Harmonic}

The measurement error percentage of the CVT under different harmonics can be obtained according to the formula (7).The PSCAD/EMTDC simulation model is built. The r.m.s value of the source voltage is $1 \mathrm{kv}$ and the phase is 0 . The simulation errors of the amplitude and the phase angle are shown in figure 4. 


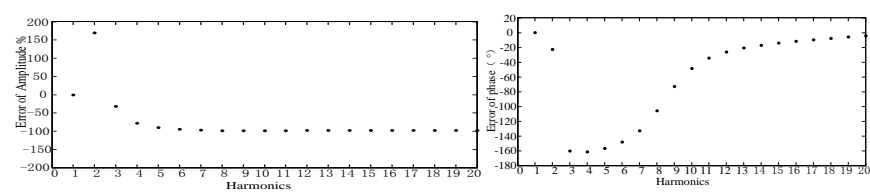

FIGURE IV. THE SIMULATION ERROR OF CVT UNDER HARMONICS

The measurement accuracy of fundamental voltage obtained by CVT is high, but the measurement error of the harmonic voltage amplitude is as high as $97 \%$ above. At the condition of harmonic, the CVT will introduce serious phase deviation. Obviously, CVT is not suitable for the measurement under harmonics.

\section{B. The Simulation of Harmonic Error by $C T$}

In this simulation, the power factor is 1 and load rate is $100 \%$, The RMS value of current source is $1 \mathrm{kA}$, phase is zero. Measurement error of the CT under different harmonics can be obtained thought simulation.

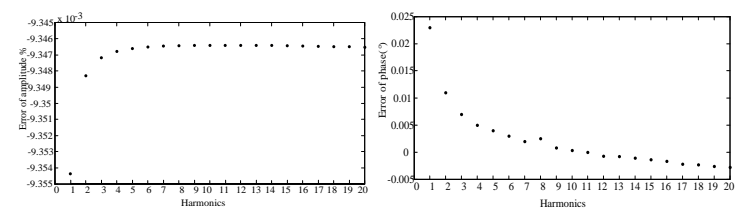

FIGURE V. THE SIMULATION ERROR OF CT UNDER HARMONICS.

In figure 5, the conclusion can be gotten that on the condition of harmonic measurement accuracy of CT is very high.

\section{Measurement Error of Electric Energy Metering System}

$110 \mathrm{kV}$ system is taken as an example, combined with the few charge for electricity, the influence of harmonics on electric economy can be illustrated.

The r.m.s value of the input voltage in electric energy metering system is $63.5 \mathrm{kV}$, phase is 0 ; the r.m.s value of the input current is $500 \mathrm{~A}$, phase is 0 . Namely, the input power of the electric energy metering system is $31.75 \mathrm{MW}$. The modulation frequency of watt-hour meter is set to $20 \mathrm{MHZ}$. The power factor of load is 0.8 . The outputs of all parts are shown in the table 1 and the measurement errors of each part are shown in table 2 .

TABLE I . THE OUTPUT OF ELECTRONIC ENERGY METERING SYSTEM UNDER FUNDAMENTAL WAVE.

\begin{tabular}{|c|c|c|c|c|}
\hline \multicolumn{2}{|c|}{ Output voltage of CVT } & \multicolumn{2}{|c|}{ Output current of CVT } & \multirow{2}{*}{$\begin{array}{c}\text { Power value of } \\
\text { watthour } \\
\text { metter }(\mathrm{kW})\end{array}$} \\
\hline $\begin{array}{c}\text { Amplitude } \\
(\mathrm{kV})\end{array}$ & Pha & $\begin{array}{c}\text { Amplitud } \\
\mathrm{e}(\mathrm{kA})\end{array}$ & $\mathrm{Pha}$ & \\
\hline 63.1941 & -0.010394 & 0.499953 & 0.022868 & 31.5940 \\
\hline
\end{tabular}

TABLE II . THE MEASUREMENT ERROR OF METERING SYSTEM UNDER FUNDAMENTAL WAVE.

\begin{tabular}{|c|c|c|c|}
\hline $\begin{array}{c}\text { Measurement } \\
\text { error of CVT(\%) }\end{array}$ & $\begin{array}{c}\text { Measurem } \\
\text { ent error } \\
\text { of CT(\%) }\end{array}$ & $\begin{array}{c}\text { Measurement } \\
\text { error of watthour } \\
\text { meter(\%) }\end{array}$ & $\begin{array}{c}\text { Measurement } \\
\text { error of the } \\
\text { system }(\%)\end{array}$ \\
\hline-0.479744 & -0.009354 & $-2.055567 \mathrm{e}-09$ & -0.489222 \\
\hline
\end{tabular}

Multiple harmonic background can be simulated by the superposition of fundamental wave with $3^{\text {rd }}, 5^{\text {th }}$ and $7^{\text {th }}$ harmonic. The r.m.s value of the fundamental wave voltage and current is set to $63.5 \mathrm{kV}$ and $500 \mathrm{~A}$; The r.m.s value of $3^{\text {rd }}, 5^{\text {th }}$ and $7^{\text {th }}$ harmonic voltage are set to $4 \%, 3 \%, 2 \%$ and their phases are 0 . The modulation frequency of watt-hour meter is set to $20 \mathrm{MHZ}$.

The r.m.s value of the input voltage is $63.592008 \mathrm{kV}$ and input current is $0.50087 \mathrm{kA}$ in electric energy metering system.

The input power $\mathrm{P}$ of the electric energy metering system is $31.848425 \mathrm{MW}$.

The outputs of all parts of are shown in the table 3 .

TABLE III . THE OUTPUT OF ELECTRONIC ENERGY METERING SYSTEM UNDER HARMONICS.

\begin{tabular}{|c|c|c|c|c|}
\hline \multirow{2}{*}{$\begin{array}{l}h^{t h} \\
\text { armo } \\
\text { nic }\end{array}$} & \multicolumn{2}{|c|}{ Output voltage of CVT } & \multicolumn{2}{c|}{ Output current of CVT } \\
\cline { 2 - 5 } & Amplitude(kV) & Phase $\left(^{\circ}\right)$ & Amplitude(kA) & Phase $\left(^{\circ}\right)$ \\
\hline 1 & 63.1941 & -0.010394 & 0.499613 & 0.019883 \\
\hline 3 & 2.56604 & -1.55907 & 0.024991 & -0.001934 \\
\hline 5 & 1.99600 & -4.62534 & 0.014994 & -0.011694 \\
\hline 7 & 1.33208 & -14.9857 & 0.004998 & -0.020107 \\
\hline
\end{tabular}

The output of Watt-hour meter is $31.672957 \mathrm{MW}$.

Each part of the metering error is shown in the table 4.

TABLE IV . THE MEASUREMENT ERROR OF ELECTRONIC ENERGY METERING SYSTEM UNDER HARMONICS.

\begin{tabular}{|c|c|c|c|}
\hline $\begin{array}{c}\text { Measurement } \\
\text { error of } \\
\text { CVT }(\%)\end{array}$ & $\begin{array}{c}\text { Measurement } \\
\text { error of } \\
\mathrm{CT}(\%)\end{array}$ & $\begin{array}{c}\text { Measurement } \\
\text { error of watthour } \\
\text { meter(\%) }\end{array}$ & $\begin{array}{c}\text { Measurement } \\
\text { error of the } \\
\text { system(\%) }\end{array}$ \\
\hline-0.470171 & -0.037328 & -0.037328 & -0.037328 \\
\hline
\end{tabular}

The charge in china is 0.6 yuan/kW.h. When charged by per unit time, the fee will reduce 105.28 yuan and the loss will reduce 922252 yuan in a year.

Comparing table $1,2,3$ and 4 comprehensively, the conclusion can be made that The measurement error of watthour meter and CT is not affected by harmonics. Under many harmonics, the phase shift of CVT caused by harmonics is very big. It can be concluded that CVT is not suitable for measuring harmonics.

\section{CONCLUSION}

This paper analyses the causes and the calculation process of the electric energy metering system's measurement error under different harmonics. By simulating the value of the electric energy metering system measurement error have been gotten, but the system measurement error and the quantitative mathematical relationship of each component need further research.

\section{REFERENCE}

[1] Yaqiao LUO, Chong HU. Influence of harmonics on power energy measurement [J]. Electric Power Automation Equipment, 2009, 5: 032. 
[2] Shaodong S, Xing W. Influence of harmonics on electric energy measurement [J]. Electric Power Automation Equipment, 2008, 28(2): 54-57.

[3] Wang P, Yang Z, ZHONG Y, et al. All-digital Power Metering System for the High Voltage Power System[J]. Automation of Electric Power Systems, 2009, 6: 018.

[4] Guerra, Fd.C.F.; Mota, W.S..Current Transformer Model. Power Delivery, IEEE Transactions on , vol.22, no.1, pp.187,194, Jan. 2007.

[5] Jayachandra Sakamuri, D. John Yesuraj. Modeling and Simulation of Capacitor Voltage Transformer Transients using PSCAD/EMTDC. PowerTech, 2011 IEEE Trondheim. June 2011. 1-8. 